\title{
Expressing Gratitude to a Partner Leads to More Relationship Maintenance Behavior
}

\author{
Nathaniel M. Lambert and Frank D. Fincham \\ Florida State University
}

\begin{abstract}
We proposed that expressing gratitude would increase positive perception of a relationship partner, thereby increasing comfort in expressing relationship concerns, which is a form of relationship maintenance. Study $1(n=159)$ showed a relationship between naturally occurring expressions of gratitude and comfort in voicing relationship concerns. Study $2(n=178)$ provided longitudinal evidence for direction of effects because Time 1 gratitude expression predicted Time 2 comfort in voicing relationship concerns, controlling for baseline comfort in voicing relationship concerns. Study $3(n=225)$ showed that expressing gratitude to a friend did increase voicing relationship concerns, compared with positive thought and neutral control conditions. In Study $4(n=74)$, we explored the mechanism through a longitudinal, experimental design and found that participants assigned to express gratitude reported higher comfort voicing concerns and more positive perception of partner than did control participants. Moreover, positive perception of partner mediated the relationship between condition and comfort in voicing relationship concerns.
\end{abstract}

Keywords: gratitude, appreciation, voicing relationship concerns, relationship maintenance, positive partner preception

Gratitude figures prominently among the positive dimensions of human experience (e.g., Emmons \& McCullough, 2004) and has become a burgeoning topic of inquiry. In their ground-breaking study, Emmons and McCullough (2003) used daily diary methods to show that those who wrote about the things they were grateful for over a 3-week period improved in mood, coping behaviors, and even physical health symptoms, which is consistent with research showing that gratitude increases satisfaction with life and decreases materialism (Lambert, Fincham, Stillman, \& Dean, 2009). Additionally, gratitude enhances sense of coherence (Lambert, Graham, Fincham, \& Stillman, 2009) and is related to lower rates of depression over time (Wood, Maltby, Gillett, Linley, \& Joseph, 2008). Other researchers have made the case that gratitude promotes prosocial behavior (McCullough, Kilpatrick, Emmons, \& Larson, 2001) or have found that gratitude increased helping behavior (Bartlett \& DeSteno, 2006; Tsang, 2006).

\section{Definitions of Gratitude}

A common definition of gratitude is the feeling experienced when a beneficiary receives a benefit from a benefactor. For example, Emmons (2004) defined gratitude as "the recognition and appreciation of an altruistic gift" (p. 9). Lambert, Graham, and Fincham (2009) found that the layperson conceives of gratitude

Nathaniel M. Lambert and Frank D. Fincham, Family Institute, Florida State University.

We express our gratitude to Steven Graham for his helpful suggestions on the design of the study and to Marlea Gwinn for her comments on a draft of this article.

Correspondence concerning this article should be addressed to Nathaniel M. Lambert, Family Institute, Sandels Building, Florida State University, Tallahassee, FL 32306. E-mail: nlambert@fsu.edu more broadly than how it is traditionally defined by researchers. In addition to this traditional type of gratitude, which they called benefit-triggered gratitude, Lambert et al. identified a broader type of gratitude that includes being grateful for all sorts of gifts in life, including the presence of cherished others in one's life (rather than for particular benefits conferred by those cherished others). They called this type of gratitude generalized gratitude and defined it as an "emotion or state resulting from having an awareness and appreciation of that which is valuable and meaningful to oneself" (p. 6). For the purpose of these studies, we conceived of gratitude as more broadly including acknowledgment of the value of another's being or behaviors in addition to being grateful for specific, conferred benefits.

\section{Gratitude in Close Relationships}

Research on gratitude in close relationships has, however, been limited. What little research exists has shown that gratitude is viewed as an important element of successful relationships. For instance, appreciation was listed as one of the most important factors contributing to a satisfying marriage according to longterm married (25-40 years) couples (Sharlin, 1996). Newly married couples also benefit from expressing gratitude in their relationships because gratitude for one's partner was related to higher marital satisfaction and better adjustment among newlyweds (Schramm, Marshall, \& Harris, 2005). Also among newlyweds, perceived positive behavior of a partner was associated with greater gratitude toward that partner on a particular day (Mikulincer, Shaver, \& Slav, 2006). Additionally, gratitude expressed between sorority sisters promoted relationship formation and maintenance (Algoe, Haidt, \& Gable, 2008). Another study found that participants who expressed gratitude to their relationship partners for 3 weeks came to see their relationship as having greater communal 
strength than did control participants (Lambert, Clark, Durtschi, Fincham, \& Graham, 2010). These studies indicated that gratitude may be an important element of relationship well-being.

Much of the attention given to gratitude in relationships has focused on the subject of domestic labor. Some research has shown that expressing gratitude (along with other forms of effective communication about domestic labor, such as listening) was the most powerful statistical predictor and discriminator of perceived fairness for 622 dual-earner wives (Hawkins, Marshall, \& Allen, 1998). Similarly, the gratitude a wife received from her husband was related to her perception that the division of labor was fair (Hawkins, Marshall, \& Meiners, 1995). Also, Klumb, Hoppmann, and Staats (2006) found that reduction in relationship satisfaction resulting from unequal division of labor disappeared after accounting for perceived gratitude for individual contributions. Berger and Janoff-Bulman (2006) demonstrated that when costs (such as sacrifices made for a partner) were perceived as appreciated by a partner, greater relationship costs were related to greater relationship satisfaction; however, when costs were not appreciated, they were related to lower relationship satisfaction. Given all the documented benefits of receiving appreciation, it is not surprising that psychologist William James (1981/1890) stated that "the deepest principle in human nature is the craving to be appreciated" (p. 313). Clearly, the desire or the need to feel appreciated is important, and perhaps craving may even be a suitable word to describe the longing people have to be a recipient of gratitude.

\section{Conceptual Model of Gratitude and Relationship Maintenance}

One way to maintain a relationship is to voice concerns to the partner so that appropriate adjustments can be made. We argue that expressing gratitude should increase this relationship maintenance behavior of voicing relationship concerns. We now place this argument into the context of the conceptual model that guides our research (see Figure 1). Path A represents the direct effect of expressing gratitude on relationship maintenance. We sought to firmly establish this main effect of gratitude on relationship maintenance through three different designs in Studies 1-3. Paths B-C illustrate the proposed indirect path through which we suspect gratitude expression would affect relationship maintenance. We tested this path in Study 4.

\section{Path A}

Our overall prediction is that expressing gratitude should increase a participant's relationship maintenance behavior, opera-

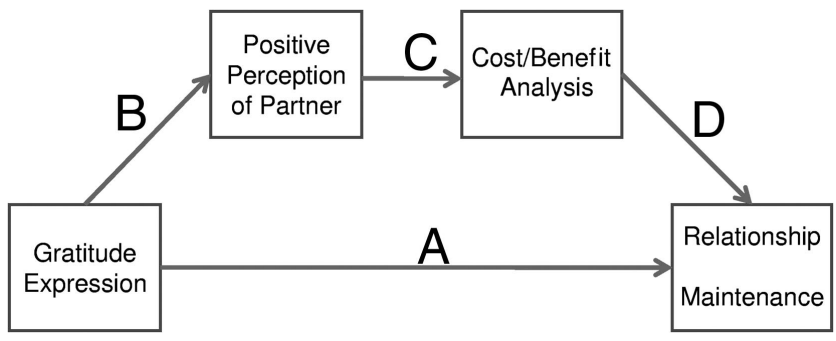

Figure 1. Theoretical model of the relationship between gratitude and relationship maintenance. tionalized in the current studies as comfort in voicing relationship concerns. Stafford and Canary (1991) emphasized the importance of openness and comfort in voicing concerns as a key aspect of relationship maintenance. We propose that expressing gratitude can be seen as a responsive action directed toward the partnerthat is, one cares enough about the partner to reassure the partner that his or her actions are appreciated and desired. Through selfperception, dissonance reduction, or both, being responsive to the partner should convince the self that it should enact additional behaviors (such as voicing relationship concerns) to maintain the relationship.

\section{Path B}

Consistent with self-perception theory (Bem, 1967, 1972), we predict that focusing on positive aspects of the relationship and increasing gratitude expression behavior should increase positive perceptions of the partner. Initially developed as an alternate explanation for dissonance theory (Festinger, 1957), selfperception theory can be considered a special case of attribution theory wherein an individual "observes" his or her own behavior and makes attributions about the motivations behind the behavior after the fact. These attributions become the attitudes that the individual endorses (Bem, 1967, 1972). Therefore, we hypothesize that increasing the frequency and regularity of expression of gratitude to a relationship partner will be associated with higher positive perception of that person.

\section{Path C}

Implicit in social exchange theory (Blau, 1964; Homans, 1961; Nye, 1979) is the notion that humans are rational beings making rational choices based on a subjective analysis of the costs and benefits of the choice (or exchange). Because the result of an exchange of gratitude is an enhanced positive perception of one's partner, this positive perception will factor into the participant's cost-benefit analysis, resulting in an outcome more favorable for the partner. Essentially, positively perceiving a partner's interpersonal qualities should result in an evaluation that the relationship is worthy of further investment.

A favorable cost-benefit analysis should result in a conscious (or subconscious) choice to invest in the long-term well-being of the relationship by engaging in relationship maintenance activities such as voicing relationship concerns, consistent with Lemay and Clark's (2008) finding that perceiving one's partner as being responsive was related to relationship promotion, which included expressing concerns about the relationship. Expressing negative emotion such as a relationship concern is also important to relationship well-being for several reasons. First, expressing negative emotion provides important information about one's needs, which may help a relationship partner know how to respond in an appropriate and caring manner (Clark \& Brissette, 2000; Clark \& Finkel, 2004; Clark, Fitness, \& Brissette, 2001). Also, expressing negative emotions to a relationship partner may signal to the partner that he or she is trusted not to take advantage of one's vulnerabilities (Graham, Huang, Clark, \& Helgeson, 2008). Finally, the expression of negative emotion is related to a sense of relationship intimacy in the individual who expressed the emotion (Graham et al., 2008; Reis \& Shaver, 1988) and has also been 
related to increased received support (Clark, Oullette, Powell, \& Milberg, 1987; Graham et al., 2008).

\section{Need for the Current Studies}

Despite the demonstrated importance of gratitude in relationships, to our knowledge no study has examined specific relationship outcomes and identified the mechanisms linking gratitude to these outcomes. Although existing studies have provided some clues that gratitude plays a role in relationships, the available data tend to be open ended or purely correlational. Therefore, whether gratitude is the cause of positive outcomes or whether it is simply the by-product of an already healthy relationship is unclear. To clarify the direction of the relationship and to test for causality, experimental designs are needed.

The literature on gratitude has emphasized the benefits of receiving gratitude (e.g., Berger \& Janoff-Bulman, 2006; Hawkins et al., 1995); however, the benefits to those who express gratitude have not been thoroughly examined. Besides its relative neglect, we chose to focus on these benefits for two additional reasons. One reason is that it should alter an individual's perception of his or her relationship partner, which would likely lead to other understudied, positive relationship outcomes. In addition, the purpose of this study was to inform future experimental work and intervention, and we perceive expression of gratitude to be a more realistic target for manipulation than receipt of gratitude. For example, in the current sample we had no experimental control over the gratitude expressed by participants' friends, but we could intervene to increase participants' expression of gratitude. For these reasons, we chose expression of gratitude, rather than receipt of gratitude, as the independent variable of interest.

\section{Hypotheses and Overview of Studies}

We had two primary hypotheses that directed our studies.

\section{Hypothesis 1}

We hypothesized that higher levels of expression of gratitude would be directly related to higher levels of relationship maintenance behaviors.

\section{Hypothesis 2}

We also hypothesized that expressing gratitude would be related to enhanced positive perception of a relationship partner, which would mediate between expression of gratitude and comfort in voicing relationship concerns, which is consistent with Collins and Miller's (1994) finding that people disclose more to someone whom they like.

We proposed that a key benefit of expressing gratitude would be the resultant enhanced positive perception of a close relationship, thus increasing the appeal of this person and the desire to maintain the relationship by addressing concerns in it. We tested these hypotheses in four studies: In Study 1, we sought to determine whether expression of gratitude would be related to the relationship maintenance behavior of voicing relationship concerns. In Study 2, we examined the direction of effects with a longitudinal design. In Study 3, we hypothesized that there would be a causal relationship between expression of gratitude and comfort in voic- ing relationship concerns, compared with positive thought and neutral control conditions. In Study 4, we again tested this relationship, this time with a longitudinal, experimental design. In addition, we proposed a mechanism-positive perception of partner-that would mediate between gratitude and comfort in voicing relationship concerns.

\section{Study 1}

The objective of Study 1 was to determine whether there was a relationship between naturally occurring expressions of gratitude and comfort in voicing relationship concerns. We hypothesized that expression of gratitude would predict comfort in voicing relationship concerns, controlling for sex.

\section{Method}

Participants. Our sample consisted of 159 participants (137 women, 22 men) enrolled in an introductory course on families and the life span who completed an online survey for extra credit. Ages ranged from 18 to 37 with a median age of 19, and participants reported about a relationship with either a romantic partner or a close friend.

Measures.

Gratitude expression in relationships. This three-item measure of behavior (Lambert et al., 2010) includes items such as "I express my appreciation for the things that my partner does for me." Participants rated their gratitude expression on a 7-point scale $(1=$ never, $7=$ very frequently $)$. Scores were coded and averaged such that higher scores indicated more comfort. The coefficient alpha for the current sample was .92 .

Comfort in voicing relationship concerns. Greene, Derlega, and Mathews (2006) defined relational self-disclosure as a "disclosure that focuses on one's relationship with another person or interactions with others" (p. 412). Comfort in voicing relationship concerns may be one type of disclosure, and we argue that addressing concerns in a relationship is an important facet of relationship maintenance. To measure the degree of comfort an individual has in expressing concerns or problems in a relationship, we created a five-item scale. Items included "I feel comfortable in making suggestions to my friend," "When I am upset about something in our relationship, I feel comfortable telling my friend," "I almost never let my friend know when he or she is doing something I do not like," "I feel safe voicing my concerns with my friend," and "I feel that I can talk to my friend about almost anything." Participants rated their comfort in voicing relationship concerns on a 7 -point scale $(1=$ strongly disagree, $7=$ strongly agree). Scores were coded and averaged such that higher scores indicate more comfort. The coefficient alpha for the current sample was .88 .

\section{Results and Discussion}

Consistent with our hypothesis, expression of gratitude $(M=$ $4.20, S D=0.74)$ was significantly related to comfort in voicing relationship concerns $(M=5.23, S D=0.75), \beta=.42, t(158)=$ 5.81, $p<.01$, even when controlling for sex, $\beta=.42, t(157)=$ $5.66, p<.01$. 
The results indicate that expressing gratitude is related to comfort in voicing relationship concerns. However, this study is somewhat limited because the findings reflect the concurrent relationship between the two variables of interest. Introducing a temporal component into the research design allows greater confidence in inferring direction of effects, because causes generally precede effects. In Study 2, therefore, we used a longitudinal design.

\section{Study 2: Longitudinal Evidence}

\section{Method}

Participants and procedure. The study initially included 224 undergraduates (178 women) who participated in the study for partial course credit. Participants ranged in age from 17 to 33 with a median age of 19 and were instructed to answer all questions about their romantic partner or most important interpersonal relationship. Of these, 179 participants completed (20\% attrition rate) all measures relevant to this study at the beginning of the academic semester and then again 3.5 months later and were included in all analyses.

\section{Measures.}

Expression of gratitude. We again used the three-item expression of gratitude in relationships measure (Lambert et al., 2010). The alpha for this measure in the current sample was .83 .

Comfort in voicing relationship concerns. To measure the degree of comfort an individual has in expressing concerns or problems in a relationship, we used the same five-item comfort in voicing relationship concerns scale as in Study 1 . The coefficient alpha for the current sample was .85 at Time 1 and .84 at Time 2 .

\section{Results and Discussion}

We used hierarchical regression analysis to determine whether initial gratitude expression predicted later perceived comfort in voicing relationship concerns when controlling for initial comfort in voicing relationship concerns and sex. In the first step, we entered the control variables of initial comfort in voicing relationship concerns and sex. In the second step, we entered baseline gratitude expression scores. Higher gratitude expression at Time 1 $(M=4.19, S D=0.93)$ was associated with higher comfort in voicing relationship concerns scores $(M=5.76, S D=1.12), \beta=$ $.35, t(180)=5.07, p<.01$. This relationship continued to be significant, controlling for initial comfort in voicing relationship concerns $(M=5.98, S D=1.06)$ and $\operatorname{sex}, \beta=.18, t(179)=3.01$, $p<.01$ (see Table 1).

Our hypothesis was supported in that we found a longitudinal relationship between expressing gratitude and later comfort in voicing relationship concerns. These findings provide some support for inferring direction of effects. However, longitudinal data are still correlational, and inferring causation requires experimental data. Only with experimental data is it possible to determine whether expressing gratitude leads to a greater perception of comfort in voicing relationship concerns. We therefore sought to obtain such data in Study 3.

\section{Study 3}

The objective of Study 3 was to reexamine the relationship between expressing gratitude and comfort in voicing relationship
Table 1

Study 2: Summary of Hierarchical Regression Analysis for Variables Predicting Time 2 Perception of Comfort in Voicing Relationship Concern Scores $(N=178)$

\begin{tabular}{lllll}
\hline \multicolumn{1}{c}{ Variable } & $B$ & $S E B$ & $\beta$ & $p$ \\
\hline Step 1 & & & & \\
T1 expression of gratitude & .39 & .08 & .33 & .01 \\
Step 2 & & & & \\
T1 expression of gratitude & .19 & .07 & .16 & .01 \\
T1 comfort voicing concerns & .51 & .06 & .55 & .00 \\
T1 sex & .28 & .15 & .11 & .07 \\
\hline
\end{tabular}

Note. $R^{2}=.11$ for Step $1(p<.01) ; \Delta R^{2}=.30$ for Step $2(p<.01)$ $\mathrm{T} 1=$ Time 1 .

concerns, this time with an experimental design. We hypothesized that participants who expressed gratitude to a friend would report more comfort in voicing relationship concerns than would participants who wrote to a friend about enjoyable joint activities or participants who simply completed the requisite measures.

\section{Method}

Participants. The sample consisted of 225 undergraduates (200 women and 25 men) who reported on their best friend. Participants ranged in age from 17 to 55 years, and their median age was 20.

Procedure. After completing demographic information, participants were randomly assigned to one of three conditions: an expression of gratitude condition, a positive thought of shared activities condition, or a no-treatment control condition.

Expression of gratitude condition. The 71 participants assigned to this condition were instructed, "Please take a minute to think of your best friend and what you really appreciate about him or her." They were then instructed to list three things that they appreciate about their best friend and were asked, "Please write a letter to your friend expressing your gratitude to him/her (please write at least 3 paragraphs)." Once they had completed their letter of gratitude, they completed a measure on comfort in voicing relationship concerns and a few other measures unrelated to the current study.

Thoughts of positive shared activities. The 78 participants assigned to this condition were instructed, "Please take a minute to think of your best friend and what you enjoy doing with him or her." They were then asked to write three things they enjoy doing with their best friend and were instructed, "Now please write a letter to your friend recollecting the things you like to do with him/her (please write at least 3 paragraphs)." Once they had completed their letter, they completed a measure on comfort in voicing relationship concerns and a few other measures unrelated to this study.

No-treatment condition. The 76 participants assigned to this condition simply completed all measures without completing any writing activity.

Measures. To measure the degree of comfort an individual has in expressing concerns or problems in a relationship, we again used the five-item comfort in voicing relationship concerns scale that included items such as "I feel comfortable in making sugges- 
tions to my friend." The coefficient alpha for the current sample was .83.

\section{Results}

Our hypothesis was confirmed by a one-way analysis of variance that revealed a significant main effect for condition, $F(2$, $222)=3.18, p<.05$. Planned comparisons revealed higher comfort in expressing relationship concerns among those in the expression of gratitude condition $(M=6.36, S D=.72)$ than among those in the positive thoughts on shared activities condition $(M=6.01, S D=1.04), F(1,222)=5.31, p<.05, d=0.39$, and the no-treatment control condition $(M=6.04, S D=0.95), F(1$, $222)=4.31, p<.05, d=0.38$.

\section{Discussion}

The results confirmed our hypothesis that experimentally manipulated expression of gratitude increased participants' comfort in the relationship maintenance task of voicing concerns. One likely reason for such a relationship is that expressing gratitude may enhance positive perception of one's friend, which in turn increases one's motivation to maintain the relationship by resolving concerns. We tested this possibility in Study 4. One limitation of Study 3 is that participants were instructed to write a letter to their friend expressing their gratitude; however, they were not required as part of the experiment to send the letter to the friend. Thus, their gratitude was not actually expressed to their relationship partner. In Study 4, we address this limitation by instructing participants to overtly express their gratitude to their friend twice a week for 3 weeks.

\section{Study 4}

The objective of Study 4 was to provide experimental, longitudinal data to address the limitations of Studies 1 and 3. Both Studies 1 and 3 were limited to one time point, which precludes inferences as to how expression of gratitude might affect positive perception of partner or comfort in voicing relationship concerns over time. This study addresses this limitation with a longitudinal design. Additionally, in Study 4 we tested a mechanism that might account for the association between expressed gratitude and comfort in voicing relationship concerns. We hypothesized that positive perception of partner would mediate this relationship. In their meta-analysis of self-disclosure, Collins and Miller (1994) found that people disclose more to someone whom they like. Thus, it seemed plausible that expressing gratitude to a friend would enhance one's positive perception or liking of a friend, which would then be related to increased desire to maintain the relationship by addressing relationship concerns. Specifically, we hypothesized that increasing the frequency and regularity of gratitude expression would increase both positive perception of partner and comfort in voicing relationship concerns and that the increase in positive perception of partner would mediate between experimentally manipulated gratitude and comfort in voicing relationship concerns.

\section{Method}

Participants. The sample consisted of 97 undergraduates who were enrolled in an introductory class on families across the life span. The final sample included in the analysis consisted of only those 74 undergraduates (59 women and 15 men) who completed all relevant measures at both time points and reported on a close friend. Participants ranged in age from 18 to 23 years, and their median age was 19 .

Procedure. Participants were randomly assigned into one of four journal activity groups (see following paragraphs). After participants completed relevant measures, they began their assigned journal activity. They completed their assigned activity twice a week and reported on the completion of the activity via an online journal. We sent them a link every Monday and Thursday morning and instructed them to write about the completion of their assigned activity.

Expression of gratitude condition $(n=18)$. This condition was the experimental condition and was designed to increase the frequency of participants' expression of gratitude. Participants assigned to this condition were given the following instructions:

\footnotetext{
For the next three weeks we would like you to focus on trying to go the extra mile to express gratitude to your friend. Between now and Thursday, please do something you wouldn't normally do to express this gratitude verbally or through writing (e.g., perhaps write an email, a kind note, tell him/her how much you appreciate something specific that he or she does). Make sure to record or remember what you did so you can report about it on Thursday.
}

Neutral (daily activities) condition $(n=17)$. This control condition was designed to provide a neutral comparison group for the other conditions and to rule out the remote possibility that simply engaging in an online journal study could affect any of the dependent variables. Participants were given these instructions:

For the next three weeks we would like you to focus on trying to go
the extra mile to think about your daily activities. Between now and
Thursday, please think about something that happened to you and
make sure to record or remember what you did so you can report
about it on Thursday.

Thoughts of gratitude condition $(n=20)$. This control condition was designed to help rule out the alternative hypothesis that simply thinking grateful thoughts about one's friend, rather than the actual behavior of expressing gratitude to him or her, is what drives any posttest differences in the dependent variables. Participants in this condition were given these instructions:

For the next three weeks we would like you to focus on trying to go the extra mile to think about things that you are grateful for about your friend. Between now and Thursday, please think about something you appreciate about your friend. Make sure to record or remember what you thought so you can report about it on Thursday.

Expression of positive memory condition $(n=19)$. This control condition was designed to help rule out the alternative hypothesis that having a positive interaction with one's friend is what causes the posttest differences in the dependent variables. Participants in this condition were given these instructions:

For the next three weeks we would like you to focus on thinking of positive memories you've had with your friend. Between now and Thursday, please think about a pleasant memory with this friend and bring it up with him/her in person, by phone, or by email. Make sure to record or remember what you did so you can report about it on Thursday. 
Participants for all conditions were given the opportunity to report their assigned activities twice a week for 3 weeks in an online journal. Within 2-3 days of completing their sixth journal entry, participants completed the baseline measures again.

Measures. All measures described here are dependent variables that were measured at Time 1 and Time 2 . Because of the experimental nature of the design, it is possible to determine whether the condition caused differences in the dependent variables of positive regard and comfort in voicing relationship concerns.

Positive perception of partner. We used the 10 positive items of the 20-item measure of interpersonal qualities (Murray, Holmes, \& Griffin, 1996) that assesses participants' positive perception of a friend. It contains positive and negative attributes from the interpersonal circle, which is a model based on the primary dimensions of warmth-hostility and dominance-submissiveness. The 10 items from the positive dimension included items such as "open and disclosing," "kind and affectionate," and "patient." Participants rated how well each of these traits described their friend on a 9-point scale $(1=$ not at all characteristic, $9=$ completely characteristic). Scores were averaged and coded such that higher scores meant higher positive regard. Coefficient alpha for positive perception of partner in the current sample was .90 at Time 1 and .88 at Time 2.

Comfort in voicing relationship concerns. To measure the degree of comfort an individual has in expressing concerns or problems in a relationship, we again used the five-item comfort in voicing relationship concerns scale. Coefficient alpha for the current sample was .93 at Time 1 and .88 at Time 2 .

Seriousness of participation. Given the length and intensity of the study, we sought to determine how seriously participants were engaged in the study. At the end of the study, we informed participants that their credit would not be affected by honest answers and asked them how often they participated in their assigned activity (e.g., doing something extra to express gratitude, thinking grateful thoughts), and they rated themselves on a scale on which 1 = never, 2 = rarely, 3 = occasionally, $4=$ fairly frequently, and $5=$ never missed once. We then excluded from the analysis eight participants who answered that they "never" or "rarely" took their assigned activity seriously.

Frequency of participation. To assess how often participants engaged in their assigned activities, we asked, "How often did you fully participate in the twice a week activities?" on a 5-point scale ranging from never to never missed once. Most (62\%) "never missed once," $20 \%$ indicated that they were "nearly perfect" in completing their activity, and the remaining $18 \%$ admitted to missing a few activities. However, nobody reported that they "never" completed their activity.

\section{Results}

Attrition. Twenty-three participants (24\%) who completed all measures at Time 1 had dropped out by Time 2. Five dropped out from the expression of gratitude condition (leaving 18), five dropped out of the thoughts of gratitude condition (leaving 20), five dropped out of the neutral condition (leaving 17), and eight dropped out of the expression of positive memory condition (leaving 19). All but three participants who failed to complete Time 2 measures dropped out right after completing the baseline mea- sures, indicating that trouble in completing their assigned activity was not likely the reason for dropping out of the study. However, to ensure that any differential attrition by condition did not bias the study results, we compared the means of those who dropped out by condition on both dependent variables. There were no significant differences on Time 1 positive perception of partner by condition, $F(3,18)=.39, p>.05$, nor were there any difference between groups on Time 1 comfort in voicing relationship concerns by condition, $F(3,18)=.90, p>.05$. In addition, we tested whether there were any differences in Time 1 positive perception of partner and Time 1 comfort in voicing relationship concerns based on completion of the study (i.e., those who dropped out vs. those who persisted). Participants who dropped out did not differ on Time 1 positive perception of partner, $t(95)=0.18, p>.05$, or on Time 1 comfort in voicing relationship concerns, $t(95)=0.96, p>.05$. Thus, attrition does not appear to be an alternative explanation for our findings because any increases in comfort in voicing relationship concerns were unlikely to be the result of participants with the lowest scores dropping out because participants who dropped out did not significantly differ initially from those who completed the study.

\section{Effect of intervention.}

Positive perception of partner. We analyzed positive perception of partner in a 4 (condition) $\times 2$ (time) analysis of covariance in which Time 1 positive perception of partner and frequency of participation served as covariates. This analysis revealed a significant main effect for condition, $F(3,68)=5.00, p=.00$. Planned comparisons revealed higher positive perceptions of the friend among those in the expression of gratitude condition $(M=5.68$, $S D=0.81)$ than among those in the thoughts of gratitude condition $(M=5.21, S D=0.93), F(1,68)=4.86, p=.05, d=0.54$; the neutral condition $(M=5.21, S D=0.67), F(1,68)=5.24, p<$ $.05, d=0.63$; and the positive interaction condition $(M=4.80$, $S D=1.07), F(1,68)=14.56, p<.001, d=0.93$. No other contrasts were statistically significant.

Comfort in voicing relationship concerns. Analysis of covariance revealed a significant main effect for condition, $F(3,68)=$ $4.29, p<.01$, even when controlling for Time 1 comfort in voicing relationship concerns and frequency of participation. Planned comparisons revealed higher comfort in voicing relationship concerns among those in the expression of gratitude condition $(M=6.26$, $S D=0.80)$ than among those in the thoughts of gratitude condition $(M=5.65, S D=1.14), F(1,68)=4.52, p<.05, d=0.62$; the neutral condition $(M=5.58, S D=0.98), F(1,68)=5.09, p<$ $.05, d=0.76$; and the positive interaction condition $(M=5.25$, $S D=1.31), F(1,68)=12.53, p<.001, d=0.93$. No other contrasts were statistically significant (see Table 2 ).

Positive perception of partner as a mediator. To test whether the positive perception of partner functioned as a mediator between experimental condition and comfort in voicing relationship concerns, we conducted a bias-corrected bootstrapping analysis recommended by Preacher and Hayes (2008). Bootstrapping involves the repeated extraction of samples from the data set (in this case, 5,000 samples were taken) and the estimation of the indirect effect in each resampled data set. The totality of all the estimated indirect effects permits the construction of a $95 \%$ confidence interval for the effect size of each indirect effect. If the values of the estimated effect sizes within the confidence interval include zero, a nonsignificant effect is indicated. 
Table 2

Study 4 Adjusted Means of Positive Perception of Partner and Comfort Voicing Concerns at Time 1 and Time 2 Controlling for Frequency of Participation $(N=74)$

\begin{tabular}{llllll}
\hline & \multicolumn{2}{c}{ Time 1 } & & \multicolumn{2}{c}{ Time 2 } \\
\cline { 2 - 3 } \cline { 5 - 6 } & & & & \\
Variable by condition & $M$ & $S D$ & & $M$ & $S D$ \\
\hline Positive perceptions & & & & \\
$\quad$ Gratitude express & 4.76 & 1.41 & & 5.68 & 0.81 \\
Gratitude thought & 5.14 & 0.80 & & 5.21 & 0.93 \\
Neutral & 5.18 & 0.83 & & 5.21 & 0.67 \\
Positive interaction & 4.97 & 1.02 & & 4.80 & 1.07 \\
Voicing concerns & & & & \\
Gratitude express & 5.26 & 1.50 & & 6.26 & 0.80 \\
Gratitude thought & 5.62 & 1.24 & & 5.65 & 1.14 \\
Neutral & 5.56 & 0.78 & & 5.58 & 0.98 \\
Positive interaction & 5.18 & 1.41 & 5.25 & 1.31 \\
\hline
\end{tabular}

Experimental condition was dummy coded such that expressing gratitude for the friend was coded as 1 and the three control conditions were coded as 0 ; the code was entered as the independent variable with Time 2 comfort in voicing relationship concerns as the dependent variable and Time 2 positive perception of partner as the mediator. The confidence interval (bias corrected) for the indirect path through positive perception of partner was $[.04, .83]$, indicating that significant mediation occurred. Also, the direct effect from condition to comfort in voicing relationship concerns became nonsignificant when adding positive perception of partner into the equation $(\beta=.07, p>.05)$, demonstrating that full mediation occurred.

\section{Discussion}

Consistent with our hypotheses, expressing gratitude for a friend increased both participants' positive perception of the partner and comfort in voicing relationship concerns to that friend over and above the effect of thinking grateful thoughts or having an unrelated positive interaction. In addition, our second hypothesis was also confirmed because the increased positive perception of partner from expressing gratitude mediated between condition and comfort in voicing a relationship concern.

The experimental nature of the design allows for causal inferences, suggesting that increasing levels of gratitude caused an increase in positive perception of partner, which then increased comfort in voicing relationship concerns. Of course, no study can rule out all alternative hypotheses; however, given our control conditions that included grateful thoughts and positive interactions, we conclude that expression of gratitude uniquely contributed to these outcomes.

\section{General Discussion}

We proposed that expressing gratitude would increase the appeal of a relationship partner, thereby increasing relationship maintenance behaviors such as addressing concerns in the relationship. We tested this idea in four studies: In Study 1, we tested whether there would be a relationship between naturally occurring expression of gratitude and comfort in voicing relationship concerns, and our data supported this relationship. In Study 2, we tested the direction of effects with a longitudinal design and found that gratitude at Time 1 predicted comfort in voicing relationship concerns at Time 2, even when controlling for baseline comfort in voicing relationship concerns.

In Study 3, we used an experimental design to provide causal evidence for this relationship and hypothesized that there would be a main effect of gratitude on comfort in voicing relationship concerns. Indeed, even compared with positive thought and neutral control conditions, expressing gratitude increased comfort in voicing concerns to a friend. In Study 4, we sought to provide additional experimental evidence, this time with a longitudinal design that proposed that positive perception of partner would mediate this relationship. Participants were randomly assigned to write about daily events, express gratitude to, discuss a positive memory with, or think grateful thoughts about a friend twice a week for 3 weeks. At the end of the 3 weeks, those assigned to the expression of gratitude in relationships condition reported a higher positive perception of their friend and more relationship maintenance behavior than did those in the other conditions, even when controlling for the baseline scores of these variables and frequency of participation in the intervention. In addition, positive perception of partner mediated the relationship between condition and comfort in voicing relationship concerns.

These findings that expression of gratitude increased positive perception of a partner may be explained in part by self-perception theory (Bem, 1967, 1972). Namely, increasing the frequency and regularity of gratitude expression behavior should lead to an increased perception of the self as being grateful for the friend's interpersonal qualities as views (perception of interpersonal qualities) come into harmony with behavior (expressing gratitude) Given the emphasis that self-perception theory places on behavior, it makes some sense that, consistent with the results of Study 4, expressing gratitude to a friend would do more to alter one's positive perception of the friend than would simply thinking about one's gratitude for the person.

However, an alternative explanation to self-perception theory is that more frequent expression of gratitude could have increased the amount of positive interaction with the friend, which is responsible for the increase in positive perception of the partner. Although we tried to account for this possibility by including a positive interaction condition, it may be that expressing gratitude elicited a specific type of positive interaction that is responsible for the increase in positive perception of partner. Future research should test whether positive and negative interaction with a relationship partner or self-perception is a better explanation of these findings.

Our second hypothesis was also confirmed because the increased positive perception of partner from expressing gratitude mediated between condition and comfort in voicing a relationship concern, which is consistent with social exchange theory (Blau, 1964; Homans, 1961; Nye, 1979) and suggests that increasing participants' positive perception of their relationship partner likely yields a favorable cost-benefit analysis of whether it is worth the participants' efforts to continue to invest in the relationship by addressing concerns in the relationship.

\section{Implications for Practitioners}

In all four studies, expressing gratitude was related to or increased participants' comfort in voicing relationship concerns. The 
findings of Study 4 indicate that expressing gratitude to a friend increased participants' positive perception of this person, which was then responsible for establishing the comfort necessary to voice relationship concerns, confirming our proposition that increasing positive perceptions of the partner would make an individual more comfortable in expressing negative emotion. Given the role of negative emotions for providing helpful information to a partner on how to act in an appropriate and caring manner toward a partner (Clark \& Brissette, 2000; Clark \& Finkel, 2004; Clark et al., 2001) and for enhancing intimacy (Graham et al., 2008; Reis \& Shaver, 1988), identifying a behavior - gratitude expression — that facilitates such expressions has important implications for intervention and therapy. Furthermore, given the important role of expressing relationship concerns for relationship maintenance in general (Stafford \& Canary, 1991), gratitude expression could be an important behavior that could be promoted to facilitate the preservation of relationships.

\section{Limitations and Future Directions}

The current studies were somewhat limited in scope because they were based on self-report data, which are subject to personal biases and provide only half of the story regarding relationship processes. For example, the current studies are not equipped to explore the effect of receiving gratitude. It seems probable that increasing the receipt of gratitude would likely also increase one's positive perception of a relationship partner, and this could be tested by obtaining dyadic data. This would be a good follow-up to the current study.

Also, the sample was limited to college student friendships, which fails to reflect the effects of gratitude expression in more mature relationships or in romantic relationships. Thus, our findings ought to be replicated in a variety of age groups and relationship types. We may learn that gratitude functions differently in these different groups.

Although a great deal of research has shown that women are more emotionally expressive than men and experience emotions more intensely and frequently than men (e.g., Fujita, Diener, \& Sandvik, 1991; Grossman \& Wood, 1993; Kring \& Gordon, 1998; Naito, Wangwan, \& Tani, 2005), we did not find a differential rate of gratitude expression by men and women in our studies, nor did we find an interaction by gender on the effect of gratitude expression on comfort in voicing relationship concerns. We suspect that this may be partly because of the imbalance in the proportion of men to women in our studies, and perhaps we did not have sufficient power to detect such differences. Future studies should further examine this with more balanced samples.

\section{Conclusion}

These studies represent the first documented attempt to experimentally test the effect of expressing gratitude on relationship outcomes in friendships. We used a wide variety of designs-a cross-sectional design, a longitudinal design, and two types of experimental design (cross-sectional and longitudinal) - to determine the effect of gratitude expression. In all four study designs, we found that expression of gratitude was related to comfort in voicing relationship concerns, an important aspect of relationship maintenance. In the final study, we proposed and found evidence for a mechanism that accounts for the association: positive perception of partner. These findings indicate that expressing gratitude may facilitate relationship maintenance by making individuals more comfortable in voicing their concerns about the relationship. Specifically, expressing gratitude can enhance positive perception of one's partner, which leads to greater comfort in voicing the concern. The current findings have important implications for clinicians and for research on interventions.

\section{References}

Algoe, S., Haidt, J., \& Gable, S. (2008). Beyond reciprocity: Gratitude and relationships in everyday life. Emotion, 8, 425-429.

Bartlett, M. Y., \& DeSteno, D. (2006). Gratitude and prosocial behavior. Psychological Science, 17, 319-325.

Bem, D. J. (1967). Self-perception: An alternative interpretation of cognitive dissonance phenomena. Psychological Review, 74, 183-200.

Bem, D. J. (1972). Self-perception theory. In L. Berkowitz (Ed.), Advances in Experimental social psychology. New York, NY: Academic Press.

Berger, A., \& Janoff-Bulman, R. (2006). Costs and satisfaction in close relationships: The role of loss-gain framing. Personal Relationships, 13, $53-68$.

Blau, P. (1964). Exchange and power in social life. New York, NY: Wiley.

Clark, M. S., \& Brissette, I. (2000). Relationship beliefs and emotion: Reciprocal effects. In N. Frijda, A. Manstead, \& G. Semin (Eds.), Emotions and beliefs: How feelings influence thoughts (pp. 212-240). Cambridge, England: Cambridge University Press.

Clark, M. S., \& Finkel, E. J. (2004). Does expressing emotion promote well-being? An argument that it depends on relationship context. In L. Z. Tiedens \& C. W. Leach (Eds.), The social life of emotions (pp. 105129). Cambridge, England: Cambridge University Press.

Clark, M. S., Fitness, J., \& Brissette, I. (2001). Understanding people's perceptions of relationships is crucial to understanding their emotional lives. In G. J. O. Fletcher \& M. S. Clark (Eds.), Handbook of social psychology: Interpersonal processes (pp. 253-278). Oxford, England: Blackwell.

Clark, M. S., Ouellette, R., Powell, M., \& Milberg, S. (1987). Recipient's mood, relationship type, and helping. Personality and Social Psychology Bulletin, 53, 94-103.

Collins, N. L., \& Miller, L. C. (1994). Self-disclosure and liking: A meta-analytic review. Psychological Bulletin, 116, 457-475.

Emmons, R. A. (2004). An introduction. In R. A. Emmons \& M. E. McCullough (Eds.), The psychology of gratitude. (pp. 3-16). New York, NY: Oxford University Press.

Emmons, R. A., \& McCullough, M. E. (2003). Counting blessings versus burdens: An experimental investigation of gratitude and subjective wellbeing in daily life. Journal of Personality and Social Psychology, 84, 377-389.

Emmons, R. A., \& McCullough, M. E. (2004). The psychology of gratitude. New York, NY: Oxford University Press.

Festinger, L. (1957). A theory of cognitive dissonance. Palo Alto, CA: Stanford University Press.

Fujita, F., Diener, E., \& Sandvik, E. (1991). Gender differences in negative affect and well-being: The case for emotional intensity. Journal of Personality and Social Psychology, 61, 427-434.

Graham, S. M., Huang, J. Y., Clark, M. S., \& Helgeson, V. S. (2008). The positives of negative emotions: Willingness to express negative emotions promotes relationships. Personality and Social Psychology Bulletin, 34, 394-406.

Greene, K., Derlega, V. J., \& Mathews, A. (2006). Self-disclosure in personal relationships. In A. L. Vangelisti \& D. Perlman (Eds.), The Cambridge handbook of personal relationships (pp. 409-427). New York, NY: Cambridge University Press.

Grossman, M., \& Wood, W. (1993). Gender differences in intensity of 
emotional experience: A social role interpretation. Journal of Personality and Social Psychology, 65, 1010-1022.

Hawkins, A. J., Marshall, C. M., \& Allen, S. M. (1998). The Orientation Toward Domestic Labor Questionnaire: Exploring dual-earner wives' sense of fairness about family work. Journal of Family Psychology, 12, $244-258$.

Hawkins, A. J., Marshall, C. M., \& Meiners, K. M. (1995). Exploring wives' sense of fairness about family work: An initial test of the distributive justice framework. Journal of Family Issues, 16, 693-721.

Homans, G. C. (1961). Social behavior: Its elementary forms. New York, NY: Harcourt, Brace \& World.

James, W. (1981). The principles of psychology. Cambridge, MA: Harvard University Press. (Original work published 1890)

Klumb, P., Hoppmann, C., \& Staats, M. (2006). Division of labor in German dual-earner families: Testing equity theoretical hypotheses. Journal of Marriage and Family, 68, 870-882.

Kring, A. M., \& Gordon, A. H. (1998). Sex differences in emotion: Expression, experience, and physiology. Journal of Personality and Social Psychology, 74, 686-703.

Lambert, N. M., Clark, M., Durtschi, J., Fincham, F. D., \& Graham, S. (2010). Benefits of expressing gratitude: Expressing gratitude to a partner changes the expresser's view of the relationship. Psychological Science, 21, 574-580.

Lambert, N., M., Fincham, F. D., Stillman, T. L., \& Dean, L. R. (2009). More gratitude, less materialism: The mediating role of life satisfaction. Journal of Positive Psychology, 4, 32-42.

Lambert, N. M., Graham, S., \& Fincham, F. D. (2009). A prototype analysis of gratitude: Varieties of gratitude experiences. Personality and Social Psychology Bulletin, 35, 1193-1207.

Lambert, N. M., Graham, S. M., Fincham, F. D., \& Stillman, T. F. (2009). A changed perspective: How gratitude can affect sense of coherence through positive reframing. Journal of Positive Psychology, 4, 461-470.

Lemay, E. P., \& Clark, M. S. (2008). How the head liberates the heart: Projection of communal responsiveness guides relationship promotion. Journal of Personality and Social Psychology, 94, 647-671.

McCullough, M. E., Kilpatrick, S. D., Emmons, R. A., \& Larson, D. B. (2001). Is gratitude a moral affect? Psychological Bulletin, 127, 249266.
Mikulincer, M., Shaver, P. R., \& Slav, K. (2006). Attachment, mental representations of others, and interpersonal gratitude and forgiveness within romantic relationships. In M. Mikulincer \& G. S. Goodman (Eds.), Dynamics of romantic love (pp. 190-215). New York, NY: Guilford Press.

Murray, S. L., Holmes, J. G., \& Griffin, D. W. (1996). The benefits of positive illusions: Idealization and the construction of satisfaction in close relationships. Journal of Personality and Social Psychology Bulletin, 70, 79-98.

Naito, T., Wangwan, J., \& Tani, M. (2005). Gratitude in university students in Japan and Thailand. Journal of Cross-Cultural Psychology, 36, 247 263.

Nye, I. (1979). Choice, exchange, and the family. In W. R. Burr, R. Hill, F. I. Nyey, \& I. L. Reiss (Eds.), Contemporary theories about the family (Vol. 2, pp. 1-41). New York, NY: Free Press.

Preacher, K. J., \& Hayes, A. F. (2008). Asymptotic and resampling strategies for assessing and comparing indirect effects in multiple mediator models. Behavior Research Methods, 40, 879-891.

Reis, H. T., \& Shaver, P. (1988). Intimacy as an interpersonal process. In S. Duck (Ed.), Handbook of personal relationships: Theory, research and interventions (pp. 367-389). Chichester, England: Wiley.

Schramm, D. G., Marshall, J. P., \& Harris, V. W. (2005). After "I do": The newlywed transition. Marriage \& Family Review, 38, 45-67.

Sharlin, S. A. (1996). Long-term successful marriages in Israel. Contemporary Family Therapy: An International Journal, 18, 225-242.

Stafford, L., \& Canary, D. J. (1991). Maintenance strategies and romantic relationship type, gender and relational characteristics. Journal of Social and Personal Relationships, 8, 217-242.

Tsang, J. (2006). Gratitude and prosocial behavior: An experimental test of gratitude. Cognition \& Emotion, 20, 138-148.

Wood, A. M., Maltby, J., Gillett, R., Linley, P. A., \& Joseph, S. (2008). The role of gratitude in the development of social support, stress, and depression: Two longitudinal studies. Journal of Research in Personality, 42, 854-871.

Received June 3, 2009

Revision received May 6, 2010 Accepted August 11, 2010 